\title{
Methodological Standardization for the Extraction of Free DNA in Plasma of Peripheral Blood
}

Ary Serpa Neto ${ }^{1}$, Marcelo Langer Wroclavski ${ }^{1}$, Jorge Luiz Freire Pinto ${ }^{2}$, Sarah Rodrigues Marsicano ${ }^{2}$, Pamela Oliveira Delgado², Patricia Granja Coelho ${ }^{2}$, Ricardo Moreno ${ }^{2}$, Viviane Aparecida Vilas Boas², Ligia Ajaime Azzalis ${ }^{3}$, Virginia Berlanga Campos Junqueira ${ }^{3}$, Auro Del Giglio $^{1}$ and Fernando Luiz Affonso Fonseca ${ }^{2,3 *}$

${ }^{1}$ Oncology Division, Department of Clinical Oncology and Hematology, ABC Medicine School (FMABC), Santo André, Brazil

${ }^{2}$ Clinical Analysis Laboratory, Department of Clinical Oncology and Hematology, ABC Medicine School (FMABC), Santo André, Brazil

${ }^{3}$ Department of Clinical Biochemistry, Federal University of São Paulo, Diadema, Brazil

\begin{abstract}
Background: Biological materials such as cells, DNA, RNA, and proteins can be recovered from blood, urine, feces, pancreatic juice and sputum of patients. Here, we described a method for free plasma DNA extraction used in our laboratory, compared it to one of the most reproduced in the literature, and also verified the effects of short time storage of plasma on DNA quantification.
\end{abstract}

Methods: We assessed DNA concentrations in four samples of peripheral blood one hour, one day and three days after plasma separation (part A). EDTA blood $(10 \mathrm{~mL}$ ) was collected from each individual (10) and the specimen was centrifuged at $1,300 \mathrm{~g}$ for $10 \mathrm{~min}$. The supernatant was transferred into polypropylene tubes, with particular attention not to disturb the buffy coat layer and the plasma was microcentrifuged at $2,400 \mathrm{~g}$. DNA extracted from plasma was quantified (part B).

Results: Mean DNA concentration after our extraction process was similar to those methods found in literature. Moreover, we found a consistently negative correlation between time after plasma collection and DNA concentrations $(r=-0.568 ; p=0.022)$.

Conclusion: We showed a new method for DNA extraction. Also, we verified that fast processing after plasma collection was necessary to produce realistic results of plasma DNA.

Keywords: Biological marker; Free DNA; Methodology

\section{Introduction}

Biological materials such as cells, DNA, RNA, and proteins can be recovered from blood, urine, feces, pancreatic juice and sputum of patients, and this fact have a big importance in the search of new biomarkers in the field of oncology principally [1]. The development of "conventional" tumor markers such as carcinoembryonic antigen and $\alpha$-fetoprotein was driven largely by introducing new methods to identify and quantify small amounts of circulating proteins relatively specific for certain types of cancer. In seeking to increase the pool of possible serologic molecular markers, several new constituents of plasma/serum are now being examined [2]. PCR-based technologies that amplify DNA copy numbers and thereby detect and quantify extremely small amounts of nucleic acids are now offering novel molecular targets for the development of cancer molecular markers.

Amounts of DNA in the blood of cancer patients were 100- to 1,000 -fold higher than in healthy subjects [3]. Detection of genetic and epigenetic modifications in tumors and matched plasma or serum DNA has demonstrated that part of this DNA was from tumoral origin [3].

Despite the increased concentration of plasma DNA in cancer patients had already being reported [3], does not exist in the literature the influence of plasma collection and centrifugation time on DNA extraction after short time storage of plasma. Moreover, we used DNA extraction's kit for whole blood to obtain free DNA from plasma. We set out to show the influence of those variables in order to ensure that after controlling analytically the time of collection, centrifugation and extraction method, one can use the concentrations of free plasma DNA in cancer studies.

Our aim was to: i) describe a methodology for free plasma DNA extraction used in our laboratory, comparing it to one of the most reproduced in the literature [4], ii) verify effects of short time storage of plasma on the final outcome of the procedure and iii) use extraction kits for whole blood to obtain free DNA from plasma by controlling the centrifugation.

\section{Methods}

The study comprised two parts. First part (part A) focused on the effects of short time of plasma separation on the concentration of total plasma DNA. To study this, we assessed DNA concentrations in four samples of peripheral blood one hour, one day and three days after the plasma collection. Our current protocol of extraction will be described below. Second part (part B) was designed to assess the differences in the final DNA concentration between our method of extraction and a well established method in the literature [4].

*Corresponding author: Fernando Luiz Affonso Fonseca, PhD, Oncology Division, Department of Clinical Oncology and Hematology, ABC Foundation School of Medicine, Av. Lauro Gomes, 2000, São Paulo, Brazil, Tel: 55-11-49935400; E-mail: fon_fonseca@yahoo.com.br

Received November 27, 2011; Accepted February 02, 2012; Published February 06, 2012

Citation: Neto AS, Wroclavski ML, Freire Pinto JL, Marsicano SR, Delgado PO, et al. (2012) Methodological Standardization for the Extraction of Free DNA in Plasma of Peripheral Blood. J Cancer Sci Ther S5:005. doi:10.4172/1948-5956.S5-005

Copyright: () 2012 Neto AS, et al. This is an open-access article distributed under the terms of the Creative Commons Attribution License, which permits unrestricted use, distribution, and reproduction in any medium, provided the original author and source are credited. 


\section{Healthy controls}

Ten normal healthy women, without history of familial diseases, attending the Clinical Department at the ABC Medical School were recruited. Antecubital venous blood samples $(10-12 \mathrm{~mL})$ were collected into EDTA tubes. Blood samples were processed in the first hour of collection and the plasma was transferred into polypropylene tubes and stored at $-20^{\circ} \mathrm{C}$ until further processing. All women signed a consent term and the study was approved by the Ethical Committee of $\mathrm{ABC}$ Medical School.

\section{Chiu et al. [4] processing}

EDTA blood $(10 \mathrm{~mL})$ was collected from each individual and the specimen was centrifuged at 1,600 g for 10 min (Megafuge 1.0R; Heraeus Instruments). Supernatant was transferred into polypropylene tubes, with particular attention not to disturb the buffy coat layer and the plasma was microcentrifuged (Eppendorf Centrifuge 5415D) at full speed $(16,000 \mathrm{~g})$.

\section{Our processing}

EDTA blood $(10 \mathrm{~mL})$ was collected from each individual and the specimen was centrifuged at $1,300 \mathrm{~g}$ for $10 \mathrm{~min}$. The supernatant was transferred into polypropylene tubes, with particular attention not to disturb the buffy coat layer and the plasma was microcentrifuged at $2,400 \mathrm{~g}$.

\section{DNA extraction}

DNA extraction was performed using a GFX ${ }^{\mathrm{TM}}$ kit (Amersham Pharmacia Biotech, Inc, USA) following the adapted protocol:

Plasma was subjected to centrifugation. In $1 \mathrm{~mL}$ of sample were added $500 \mu \mathrm{L}$ of extraction solution and the mixture was incubated at room temperature for 10 minutes with occasional agitation. This mixture was eluted five times by the same column of the kit, and after multiple elutions, material was centrifuged at $8,000 \mathrm{~g}$ for one minute and the remainder present in the collection tube was discarded. 500 $\mu \mathrm{L}$ of washing solution was added to wash the column and it was centrifuged at 14,000 $\mathrm{g}$ for three minutes and eluate present in the collection tube was discarded to clear the column of interferences and improve the quality of DNA to be eluted in the next step. DNA elution consisted of the addition of $20 \mu \mathrm{L}$ of MiliQ water at $70^{\circ} \mathrm{C}$ on the column and it was centrifuged at $8,000 \mathrm{~g}$ for one minute.

\section{DNA quantification}

DNA extracted from plasma was quantified using the PicoGreen dsDNA Quantification Reagent Kit (Molecular Probes, Leiden, The Netherlands). PicoGreen specifically binds to dsDNA and after excitation at $485 \mathrm{~nm}$ the complex dsDNA/PicoGreen fluorescence is detected at $538 \mathrm{~nm}$. A calibration curve ranging between 0.2 and 0.0005 $\mathrm{ng} / \mu \mathrm{L}$ using DNA at a known concentration $(100 \mu \mathrm{g} / \mathrm{mL})$ provided in the kit was included in each experiment. The concentrations of the samples were calculated twice at 2 different dilutions. Five microliters and $10 \mu \mathrm{L}$ of DNA were diluted in a $200 \mu \mathrm{L}$ reaction mixture containing $1 \mathrm{X}$ TE $(10 \mathrm{mM}$ Tris-HCl, $1 \mathrm{mM}$ EDTA, pH 7.5) and PicoGreen (1:400). After 5 min of incubation, the reaction was excited and the fluorescence was recorded with a fluorometer (Labsystem, Helsinki, Finland). Plasma DNA concentrations were estimated using the calibration curve. An average of the 2 concentrations obtained with the
2 dilutions was calculated. If the concentrations at 1 in 40 and 1 in 20 dilutions differed, the concentrations were measured a second time. If the results were still discordant, the sample was not included in the analysis.

\section{Statistical analysis}

Part A of the study was analyzed using non-parametric paired test (Wilcoxon test) and non-parametric correlation coefficients (Kendall's $\tau)$. Results from the two methods (part B) were compared with nonparametric independent test (Mann-Whitney). Thus, we constructed folded empirical cumulative distribution plot ("Mountain plot") which is the plot of the difference between the reference method and the tested method in the x-axis (Chiu's method - Our method) and percentage of found results in the y-axis. Finally we compared the results by BlandAltman procedures [5].

All statistical analyses were made using the statistical software package SPSS (v16.0; SPSS, Chicago, IL), and MedCalc software. Statistical significance was considered at $p<0.05$.

\section{Results}

\section{Part A: Effects of time between collection and processing}

DNA concentration after short time of plasma storage is exposed in Figure 1. We found a consistently negative correlation between time after plasma collection and DNA concentrations (Kendall's $\tau r=-0.568$; $p=0.022$ ) with a linear regression equation of DNA concentration $=-$ $0.212-0.694 \times$ Time after collection $(p=0.012)$.

\section{Part B: Validation of our methodology}

Figure 2 shows sediment obtained after the second centrifugation from both methodologies. Mean DNA concentration after our extraction process was similar to that found after Chiu's method (3.91 $\pm 6.27 v s .3 .49 \pm 5.84 \mu \mathrm{g} / \mathrm{mL}$, respectively; $p=0.169)$ and the correlation found was also statistically significant $(r=0.993 ; p<0.0001)$ (Figure 3 ).

Figure 4 shows the folded empirical cumulative distribution plot ("Mountain plot") and it is possible to verify that approximately $45 \%$ of the results was similar between the two methods (median $=-0.2$ ).

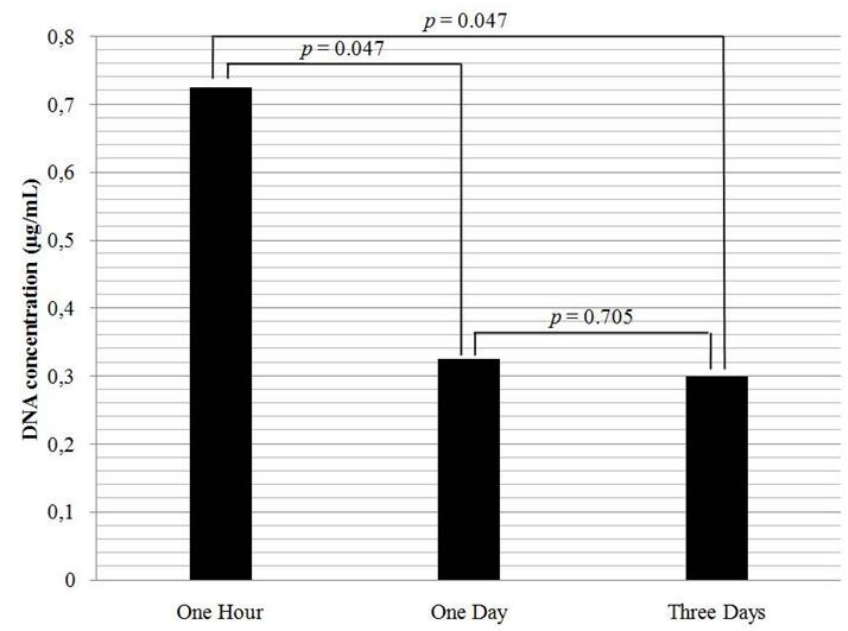

Figure 1: Difference between DNA concentrations extracted after one hour one day and three days of collection. 
The concordance correlation coefficient between two methods was 0.987 (CI95\%: 0.959 - 0.996). Precision (Pearson $\rho$ ) and accuracy (Bias correction factor $\mathrm{C}_{\mathrm{b}}$ ) were, respectively, 0.992 and 0.994 . Finally, visual inspection of Bland-Altman plot (Figure 5) shows that there is no systematic bias in the measurement concordance for Chiu's and our method of extraction. All values were distributed in the acceptable limits of variation, corroborating that both methods of extraction produced similar results of DNA concentration.

\section{Discussion}

Data analysis from part A revealed that time delay in plasma collection and procession had significant impact on DNA quantification. In part B, we showed that results produced by our method of extraction were similar to those produced by Chiu's method. Our results also suggest that is possible to use extraction kit for whole blood DNA to free plasma DNA. However, it is necessary to perform centrifugations protocols able to separate some interference and impurities. Our two steps of centrifugation were able to separate and getting high concentrations of plasma DNA and it can be used in future reactions such as q-PCR and PCR.

Circulating extracellular DNA can be found in healthy people and people with nonmalignant diseases, including systemic lupus erythematosus, rheumatoid arthritis, pulmonary embolism, or myocardial infarction, and various malignancies, including small cell

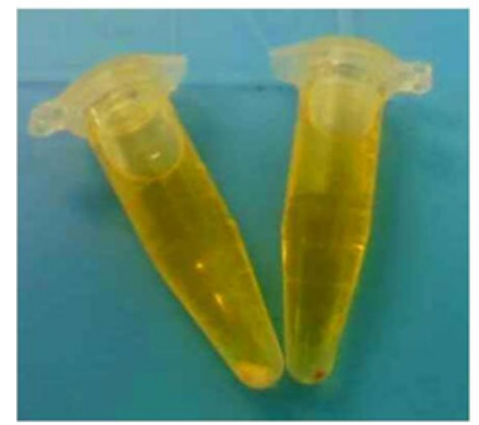

Figure 2: Sediment formed after the second centrifugation in our method (in the left) and in the Chiu's method (in the right).

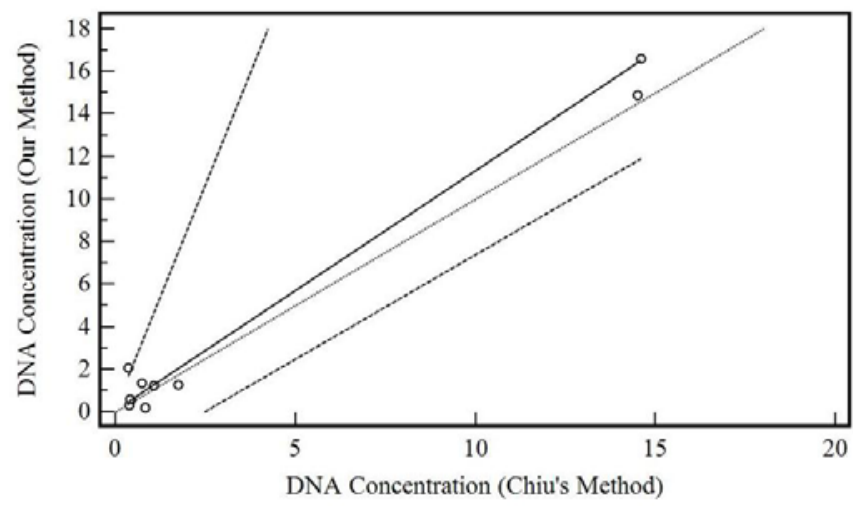

Figure 3: Passing and Bablok regression of DNA concentration after our method of extraction ( $y$-axis) and Chiu's method ( $x$-axis). Passing and Bablok regression equation: DNA concentration by our method $=0.066+1.127 x$ DNA concentration by Chiu's method. Cusum test for linearity: No significant deviation from linearity $(p>0.1)$.

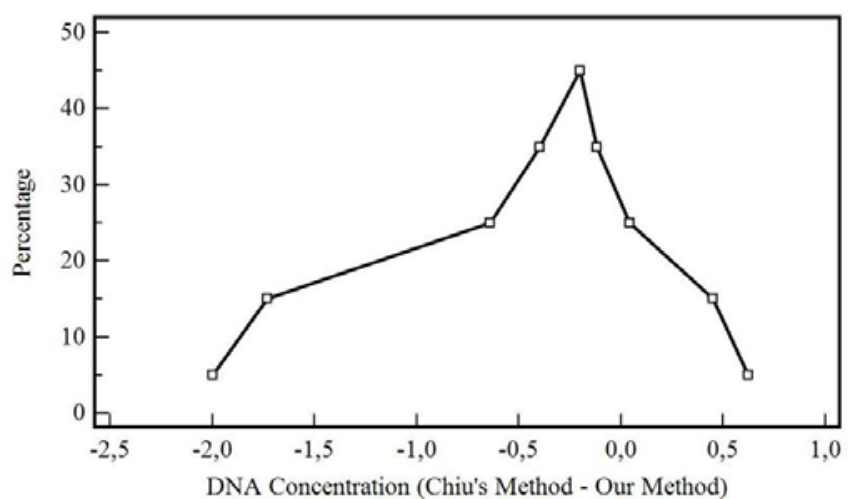

Figure 4: Folded empirical cumulative distribution plot ("Mountain plot").

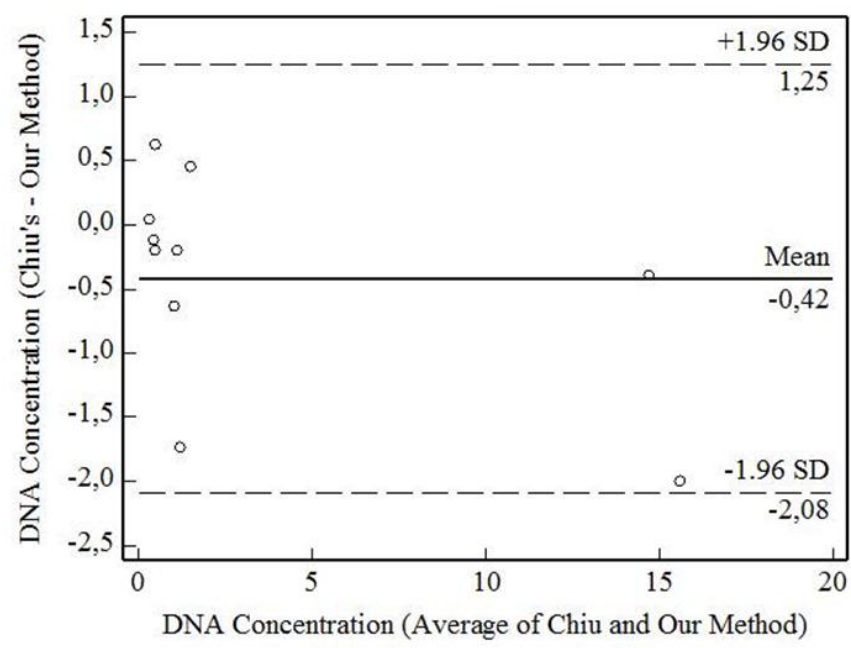

Figure 5: Bland-Altman plot.

lung cancer and non-small cell lung cancer [6]. In addition, trauma and therapeutic procedures may also lead to release of free DNA into the circulation [6]. However, actual origin remains unknown. Considerable controversy exists concerning the reference concentrations of DNA in healthy controls, with reported values ranging from barely detectable concentrations to a few micrograms per liter [7]. Most of the authors of the published reports, however, agree that DNA concentrations are higher in people with various malignant and nonmalignant disorders than in healthy controls [6]. In healthy people, it can be presumed that circulating DNA originates from lymphocytes or other nucleated cells, but its origin in malignancies is still unknown [7]. Many mechanisms have been postulated that might explain the release of DNA into the circulation by tumor-host or tumor-virus interactions $[6,8]$.

Many studies have addressed the use of serum/plasma DNA for disease management [9]. In terms of DNA quantification, however, there is no standard. In the past, colorimetric or fluorometric assays used reagents such as diphenylamine, that when added to the patient's plasma/serum produced a color change which degree correlated with DNA concentration [9]. Poor specificity and sensitivity of the reagents and their side reactions with other components in samples had limited their use in quantitative analyses. Other assays, such as hemaglutinin 
inhibition, complement fixation, and diffusion in agarose, also did not provide advantage in terms of sensitivity [10]. Using the more sensitive RNA-DNA hybridization, RIA, and counter immunoelectrophoresis assays, nanogram amounts of circulating DNA can be quantified. With real-time PCR and PicoGreen double-stranded DNA quantification assays, it is now possible to quantify picogram amounts of circulating DNA $[8,11]$.

It seems likely that over the next decade plasma DNA will join a growing band of clinically useful molecular markers of cancer. Of particular interest is the growing belief that the study of bodily fluids such as plasma/serum may provide a more global picture of the abnormalities present in the tumor [12].

However, there are still several questions about this marker, principally in the methodological field [13]. Why should there be an apparent predilection of the tumor-related DNA to enter the circulation? How do the tumor-derived nucleic acids enter plasma? What protects plasma DNA from circulating DNases? How crucial are the procedures used to prepare samples for analysis? How will the plasma-based techniques described here perform when transferred to other bodily fluids?

At a technical level, a variety of analytical and pre-analytical issues remains to be addressed. For example, different groups of investigators have used different nucleic acid extraction protocols for plasma and serum. There have been relatively few quantitative studies formally comparing the performances of these different extraction protocols. For future large-scale application of plasma/serum DNA technology, automation of nucleic acid preparation will be necessary. Nucleic acid preparation systems are beginning to be evaluated by several investigators in the circulating nucleic acid field [14]. Pre-analytical issues, such as a formal comparison of plasma and serum and the effects of different centrifugation protocols, are also being explored $[4,15]$.

Our results showed that it is possible to use whole blood extraction DNA's kit for plasma/serum by controlling time of collection and centrifugation, in other words pre-analytical issues. Many authors report that pre-analytical phase has the largest frequency of errors associated with laboratory tests [16,17]. According to criteria used to determine the errors associated with pre-analytical issues, these may represent more than $90 \%$ of the total error, which indicates the need to focus on this step in the planning study $[18,19]$ of free plasma DNA once there is no consensus on the results of concentrations and analytical methods in studies of patients with cancer.

Despite the fact that in our study levels of free plasma DNA were comparable to those found by other authors $[4,20,21]$, in our opinion, it would be important the development of standardized method for sample collection and DNA isolation in order to avoid pre-analytical errors and values ranging from barely detectable concentrations to a few micrograms per liter. Moreover, Sozzi et al. [22] have shown that prolonged storage of both isolated DNA and whole plasma samples led to substantial DNA degradation as measured by real-time PCR-based analysis. On the other hand, our study shows that short time storage also can lead to plasma DNA degradation.

Here we showed a simple, controlled and efficient method of DNA extraction adapted from plasma. Moreover, we conclude it is necessary to control pre-analytical laboratory indicators of performance to qualify improvement of laboratory testing. Also, we suggest that a fast processing after plasma collection (one hour) is necessary to produce realistic results of plasma DNA.

\section{Conflict of Interest}

Authors declare no conflict of interest and financial support.

\section{References}

1. Sidransky D (1996) Advances in cancer detection. Sci Am 275: 104-109.

2. Johnson PJ (2001) A framework for the molecular classification of circulating tumor markers. Ann N Y Acad Sci 945: 8-21.

3. Anker $P$, Stroun $M(2000)$ Circulating DNA in plasma or serum. Medicina (B Aires) 60: 699-702

4. Chiu RW, Poon LL, Lau TK, Leung TN, Wong EM, et al. (2001) Effects of bloodprocessing protocols on fetal and total DNA quantification in maternal plasma. Clin Chem 47: 1607-1613.

5. Bland JM, Altman DG (1986) Statistical methods for assessing agreement between two methods of clinical measurement. Lancet 2: 307-310.

6. Pathak AK, Bhutani M, Kumar S, Mohan A, Guleria R (2006) Circulating cellfree DNA in plasma/serum of lung cancer patients as a potential screening and prognostic tool. Clin Chem 52: 1833-1842.

7. Koffler D, Agnello V, Winchester R, Kunkel HG (1973) The occurrence of singlestranded DNA in the serum of patients with systemic lupus erythematosus and other diseases. J Clin Invest 52: 198-204.

8. Barnett EV (1968) Detection of nuclear antigens (DNA) in normal and pathologic human fluids by quantitative complement fixation. Arthritis Rheum 11: 407-417.

9. Kamm RC, Smith AG (1972) Nucleic acid concentrations in normal human plasma. Clin Chem 18: 519-522.

10. Steinman CR (1975) Free DNA in the serum and plasma from normal adults. $J$ Clin Invest 56: 512-515.

11. Leon SA, Green A, Yaros MJ, Shapiro B (1975) Radioimmunoassay for nanogram quantities of DNA. J Immunol Methods 9: 157-164.

12. Johnson PJ, Lo YM (2002) Plasma nucleic acids in the diagnosis and management of malignant disease. Clin Chem 48: 1186-1193.

13. García-Olmo D, García-Olmo DC (2001) Functionality of circulating DNA: the hypothesis of genometastasis. Ann N Y Acad Sci 945: 265-275.

14. Costa JM, Ernault P (2002) Automated assay for fetal DNA analysis in materna serum. Clin Chem 48: 679-680.

15. Lui YY, Chik KW, Chiu RW, Ho CY, Lam CW, et al. (2002) Predominant hematopoietic origin of cell-free DNA in plasma and serum after sexmismatched bone marrow transplantation. Clin Chem 48: 421-427.

16. Wallin O, Söderberg J, Van Guelpen B, Stenlund H, Grankvist K, et al. (2008) Preanalytical venous blood sampling practices demand improvement--a survey of test-request management, test-tube labelling and information search procedures. Clin Chem Acta 391: 91-97.

17. Carraro P, Plebani M (2007) Errors in a stat laboratory: types and frequencies 10 years later. Clin Chem 53: 1338-1342.

18. Guidi GC, Lippi G, Solero GP, Poli G, Plebani M (2006) Managing transferability of laboratory data. Clin Chim Acta 374: 57-63.

19. Lippi G, Guidi GC, Mattiuzzi C, Plebani M (2006) Preanalytical variability: the dark side of the moon in laboratory testing. Clin Chem Lab Med 44: 358-365.

20. Gormally E, Caboux E, Vineis P, Hainaut P (2007) Circulating free DNA in plasma or serum as biomarker of carcinogenesis: practical aspects and biological significance. Mut Res 635: 105-117.

21. Beck J, Urnovitz HB, Riggert J, Clerici M, Schütz E (2009) Profile of the circulating DNA in apparently healthy individuals. Clin Chem 55: 730-738.

22. Sozzi G, Roz L, Conte D, Mariani L, Andriani F, et al. (2005) Effects of prolonged storage of whole plasma or isolated plasma DNA on the results of circulating DNA quantification assays. J Natl Cancer Inst 97: 1848-1850. 